\title{
Indigenous Knowledge and the African Way Forward: Challenges and Opportunities
}

\author{
Beyuo Alfred Naamwintome, David Millar \\ ${ }^{1}$ Department of Community Development, Faculty of Planning and Land Management, University for \\ Development Studies, Tamale, Ghana \\ ${ }^{2}$ Department of African and General Studies, Faculty of Integrated Development Studies, University for \\ Development Studies, Tamale, Ghana \\ Email: beyuo5@ymail.com, millarad1@yahoo.com
}

Received 10 March 2015; accepted 24 March 2015; published 30 March 2015

Copyright (C) 2015 by authors and OALib.

This work is licensed under the Creative Commons Attribution International License (CC BY).

http://creativecommons.org/licenses/by/4.0/

(c) () Open Access

\begin{abstract}
Indigenous knowledge exists and particularly in Africa and is being challenged as science and this negatively influences the harnessing of it globally. The study focused on the history of knowledge as science and the evolutionary analysis of science as a body of knowledge, within a Grounded Theory approach. The findings revealed that indigenous knowledge is a body of knowledge like the western science and has survived the custodians of this body of knowledge for generations; it dictates the progress and the well-being of the knowledge community. The study also revealed that colonialization and globalization have negatively influenced the recognition of indigenous knowledge and hence its utilization. The study recommends the deschooling and reschooling of African's scholars who have the potential of ensuring that the development of Africa reflects the African cultural, social and spiritual context.
\end{abstract}

\section{Keywords}

Indigenous Knowledge, Africa Culture, Endogenous Development

Subject Areas: Education, Sociology

\section{Introduction}

Sociologists and anthropologists from the western world have studied Africa and its peoples as objects of interest relating to their fields of work embedded in the academic, political, economic and cultural context of colonialism and post colonialism. The African continent even though has obvious differences among regions and ethnic groups, it also has common elements in the way, for instance, African people see themselves, the way they know and organize themselves [1], and this is strongly demonstrated in traditional knowledge and values 
which are important driving forces in the decision-making and development activities of the people. The recent upsurge of interest in knowledge of indigenous peoples [2] [3] has challenged the assumed superiority of western science over the sciences that have their roots and dynamics in Africa (and Asia, America and other regions). The challenge is for schooled African scholars to (re)value, give recognition, and articulate their niches in the world of science today. For instance, how does the African way of knowing relate to the claims of rationality, objectivity and universality of western sciences?

This is an invitation for us as colleagues who have been schooled by the western world to put our knowledge on the pedestal of scholarship in the interest of sustainable development. We need to move away from the feeling of mediocrity to a collegial realm with our western counterparts (as the Asian scholars are doing). These are part of the expressions and discourses of an African renaissance according to [2] [3] and these present challenges and implicit opportunities.

A number of African and Africanist writers have made their observations on African knowledge and its relation with conventional or mainstream knowledge. One perspective suggests that the African way of knowing should be integrated into the mainstream whilst another implies that the African way of knowing is scienceseparate from the mainstream but equal.

In the theory of African knowledge, the world is centered upon the "self" and this African culture does not assume that reality can be perceived through reason alone. There are other modes of knowing, such as, imagination, intuitive experience, and personal feelings. This is the deepest expression of the African cultural reality and this is through art, myths, and music.

The other basic view about nature held by the traditional African is that life-force permeates the whole universe and that matter and spirit are an inseparable reality. The traditional African has no definitions for such life-forces but only understands and describes them in terms of their functions. For instance, the soul is the individual will, his thought, conscience and judgment. Unlike the European, the traditional African does not even say that the soul is the kind of entity that goes to heaven or hell after death. When an individual soul is compatible with other individuals, it is pure and there is peace and harmony. When it is not compatible with others it is impure and there is no peace and no harmony [1].

Emegiawali suggests that the African way of knowing particularly contextual knowledge seems to be relatively less transferable than the conventional science, given its holistic socio-cultural and even spiritual dimensions [4]. The African way of knowing appears to be largely communitarian in terms of discovery and experimentation and the mode of transmission and sharing is often collective rather than individualistic. Embedded in the products and services associated with the African way of knowing are proprietary systems which are often more flexible and negotiable than its western counterpart in some cases and non-existent in others. The engine of growth and sustenance for the traditional African is never the market, the profit motive or the large-scale mass production and economies of scale as is the case with the west but a production system which is valued beyond economics [1]. The community is also a source of strength for the African way of knowing in terms of the discovery process and knowledge production.

Goduka characterizes African knowledge as spiritually centered wisdoms [5]. In the traditional African view the universe is a spiritual and a material whole in which all beings are organically interrelated and interdependent. In the process of reclaiming/affirming our indigenous stories, cultural identity and voice, we need to decolonize our minds. She suggests that educators must move beyond a focus of specialization to holistic knowledge, from materialism to spirituality; from a focus on structures to understanding processes and from objectivity to subjective methods of enquiry.

Many of the contemporary African writers on African knowledge and science argue in favour of a process of decolonialization; deschooling and reschooling. Weredu indicates that this decolonialisation is aiming at divesting African philosophical thinking of all undue influences emanating from our colonial past [6]. He is quite critical of the western domination in Africa, but also indicates that it would be unwise to reject all potentially positive things from the West. Also Goduka warns of the possibility to over-romanticize cultural and spiritual values of the pre colonial past, but maintains that the spiritually centered wisdoms should be seen as the springboard from which the current system of education can begin. "Anything short of this shall continue to plague us and continue to make our education contextually irrelevant and culturally and spiritually insensitive because it is disconnected from the cultural, social, spiritual political and economic realities” [5] [6].

The socio-religious lives of Africans are well grounded in their culture and expressed in strong social bonds between their lineages [7] and their basis of knowledge is guided by ontology, gnoseology, axiology and 
epistemology with respect to this knowledge community as is the case with any ethnosciences such as the western science. These are the features of an acceptable form of knowledge or science according to the knowledge community and these features prominently in the traditional African knowledge systems [1].

As a community of African society, people and especially the indigenous people view the world as a space for the living and who under the guidance of their ancestors live better lives and thus secure the chance of joining them after death and this is their aspiration which is attainable if good relationship and good social relation are maintained between them and their ancestors and neighbours respectively. For instance, according to McCoy [8], the Dagaara are God-conscious people who approach Him through their ancestors or the spirits of the land or the earth. These good relations are realized or sustained and have come to be learned and kept for their wellbeing.

Gnoseology is well known among indigenous Africans with established measures to drive it home. According to Emegiawali as cited [1], the African way of knowing to some extend is relatively less transferable than conventional science, given its holistic socio-cultural and even spiritual dimensions. For instance, at the attainment of certain status in the African society, the benefits and sanctions are learning points and are relatively less transferrable and articulated for instance in songs, proverbs and dirges.

In the African context, axiology is cherished and ensured that it is maintained at every group level. Local knowledge and values are the main driving force for rural people's decisions especially on land use, food production, community management, health practices, religious practices, teaching, learning and experimenting according to [6] and thus should be the main point of articulation for development activities and development workers. In Africa, values are cherished and ancestor-, ethnic-, community- or family- and totemic-centric. Thus actions or inactions that will mar values or bring disrepute to a group are despised and hence knowledge in relation to socio-religious activities is strongly guarded collectively so as to promote the forms of learning in the traditional African context.

Epistemology is also well established in the African traditional setting. For instance, there are or there exist vibrant institutions and indigenous knowledge system around which the local people organize their knowledge, lives and livelihoods especially for instance the clan system but these have been largely ignored by both government and non-governmental organizations in their bid to support the poor in poverty reduction and natural resources conservation Programmes [9] and this has implication for the success of these programmes. In the traditional African context for instance, issues are expressed and can only be understood from a particular worldview and thus, according to the tradition, expressions are socio-cultural relation-based and these are valued beyond economics. In the context of Africa, rural people have an integrated body of knowledge and practices and this body of knowledge is perpetually reconstructed from generation to generation and over time and space covering various livelihoods and life-encountered experiences according to [1] and this belief system serves as the basis for the existence of the African.

The traditional belief systems have been and are still the roots and branches of the knowledge systems of rural people in Africa and anybody of knowledge is usually judged based on this knowledge system and this is strongly maintained in Africa. Schooling of the schooled Africans has been in the context of western science which has been built within a specific worldview (ontology), methodology of learning (gnoseology), value system (axiology), and has generated a specific theoretical framework (epistemology) that is assessed and accepted by a knowledge community and this has detached the beneficiaries (schooled Africans) of this schooling in context from the knowledge system of rural or traditional Africans.

It is with this strong urge that, there is the need to deschool and reschool especially the African scholars harnessing the challenges and the opportunities if development is to be premised on our cultural, social and spiritual context. It is on the basis of this that, the paper employed evolutionary analysis of science as a body of knowledge in the context of grounded theory approach, reviews literature in the context of Africa past and present, learning and knowing system as results and discussion, conclusions and recommendation.

\section{Theoretical Framework}

The framework adopted for this paper delved into the history of forms of body of knowledge as sciences and evolutionary analysis of science as a body of knowledge, within a Grounded Theory approach which is a general methodology for developing theory that is grounded in data systematically gathered and analyzed from interrelated concepts [10]. A paper which is guided by this theory seeks no representativeness to achieve statistical generalisability but rather aims to describe, explain and has the potential of predicting phenomena based on empirical data. A paper of this sort typically leads to theory/ies that pertain/s to specific aspects of the phenomenon 
being studied and thus employs comparative, iterative, and interactive method [11]. Hence the theories of the various models of forms of body of knowledge are analysed and confronted with contemporary findings. This paper or the study was triangulated with empirical data collected in the field and an extensive literature review.

\section{Literature Review (Africa's Past and Present)}

There are many different cultures, and many differences within cultures in Sub-Saharan Africa. Historic developments, demographic and ecological differences, as well as economic opportunities, colonial impact and religious missionary activities, to mention but a few factors, have resulted in a diversity of lifestyles, professional practices, values, religions and knowledge systems. Africa has a diversity of ecosystems, ranging from extensive mountain areas, savannah and dry land areas, to lowlands, coastal plains and tropical forests. Nomadic peoples often compete for land and water resources with sedentary peoples and the urban population is increasing and a considerable number of large cities exist. Traditional religions have common elements, but there is also a great variation in rituals, traditional institutions and leadership structures and these are often combined with, or have been replaced by dominant bodies of knowledge such as Christianity or Islam. As a result, a great number of different religious denominations can be observed and yet, Sub-Saharan Africa has a lot in common, as its peoples have known a great number of migrations across the continent. Although there are more than a thousand ethnic groups, many of them have similar origins or historic relationships. The population has also a predominantly rural background, and even today agriculture remains the main occupation, many African soils are aged and tend to be quite poor and with a harsh climate, African agriculture is complex, diverse, and risk-prone.

The first anatomically modern human emerged in the southern part of Africa. The first African people hunted a wide range of animals, and learned the use of fire to control vegetation. During the last glacial period Africa was not covered with ice, but, as much of the earth's water reserve was frozen, endured drought. Evidence exists that around 9000 years ago, sorghum, millet, rice, yam, oil palm, as well as cattle were domesticated, while barley was introduced from western Asia. The first domestication took place in the territory between the Sahara and the Equator. Poultry is observed to have the highest density in Burkina Faso and the highest ratio of it to human on the continent of Africa. Increase in poultry population has kept pace with human population expansion of $3 \%$ per annum according to [12]. This animal is so vital especially to the lives of Africans with respect to religion and social relations that they determine the values and the scientific methods of their production which are based on culture. For instance, Egyptians had mastered the technique of artificial incubation and also, Western aid workers in Mali discovered a failed attempt to replace the scrawny native birds because of its religious importance with imported Rhode Island Reds according to [13]. The spread of farming and herding south of the Equator was a long and gradual process, impeded by the dense forests and parasites, especially the tsetse fly.

The colonial past has had a strong impact on the indigenous cultures and peoples. It intended to replace traditional knowledge and beliefs with western knowledge and that has limited the African capacity to solve their own problems and to develop technologies and skills that builds their own ways of knowing. In Africa, pre-colonial and post-colonial Africans survived on traditions and practices which are disregarded due to Western scientific research and development influence [14]. This aspect of colonisation was not very successful however, since the continent has a low level of literacy and few people are educated or schooled in the western style. Traditional knowledge is still widely practiced and co-exists with the formally accepted western knowledge and this serves as an opportunity. The systems of governance of most of the present nation states, established less than 50 years ago, often reflect more aspects of the colonial systems than of the pre-colonial or indigenous systems. The same holds for the legal system and the education system. Yet, the efforts of the colonisers and missionaries over the past centuries, to introduce alien concepts and rituals, have not been able to suppress the values attached to ancestors, funerals, and many other traditional practices. To a large extent, ancestral knowledge determines the way of farming and social organisation. Most health practices in rural Africa today are based on traditional healers and knowledge, using a wide range of herbs and rituals. Africans, also the educated, make use of these traditional health services widely, if possible in combination with western health care.

Africa is changing fast and there exists a mix of dominantly traditional, dominantly modern and more hybrid subcultures. Some aspects of indigenous knowledge are expressed openly, whilst other aspects are secretive and hidden from outsiders. Many studies about African worldviews and indigenous knowledge either stress the positive aspects, or strive to show the limitations and negative aspects. The first written anthropological studies on Africa often included biases and Eurocentric prejudices, which, in part, have been corrected later.For instance in Rwanda, the white fathers saw the socio-political structure as promoting and reinforcing the colonial Germans; a 
reflection of social injustice. This position was viewed differently by the Germans and thus "love-hate" relationship ensued and this was manipulated by both sides (the white fathers and the Germans) at the expense of the Rwandan society and this eventually led to the genocide in 1994 [15], a conflict which had an impact on development. Even today in Africa, institutional science is taught in the context of a Eurocentric paradigm which carries along with it arrogance, disdain, disrespect for African knowledge.

Romanticising indigenous knowledge, however, is not a good basis (for endogenous development either) as any knowledge system in the world like, African ways of knowing will have progressive and retrogressive aspects. Phenomena such as overexploitation of natural resources, land use practices that have detrimental ecological effects, gross inequalities between men and women, misuse of their position and knowledge by political and local leaders, traditional forms of conflict resolution and warfare are aspects which need to be observed and together with the positive aspects, be brought into the dialogue for enhanced performance and this must be informed by the Cosmovision of the African.

\section{Cosmovision and Various Forms of Knowledge}

Nature, Peoples, and the Spiritual are prominent features within the African traditional worldviews. Often a hierarchy between divine beings, spiritual beings, especially the ancestors, men and women, and natural forces, such as climate, disease, floods, soil, vegetation, animals, is indicated. These Cosmovisions give rise to several rituals in which the elders, the priests, soothsayers and spiritual leaders play a prominent role. Cosmovision, to a large extent, dictates the use of resources for instance, the way land, water, plants and animals are to be used, how decisions are taken, problems are solved, experimentation takes place and how rural people organise themselves [16] [17].

For the traditional people in Northern Ghana gods, spirits, ancestors, spiritual and political leaders, sacred groves, lands and shrines, ritual crops and animals, food items and cash crops are all interrelated. Obviously dominant knowledge such as Christianity, Islam and western education have influenced the Cosmovision of the Africans, especially those with formal education.

According to [18], for the Shona of Zimbabwe, the human world, the natural world and the spiritual world are linked. The natural world provides the habitat for the spirits and sends messages from the spiritual world to the human world. The spiritual world provides guidance, punishment and blessing to the human world. People therefore have to relate to both the natural and the spiritual world.

From these examples of traditional Cosmovisions in two countries as far apart as Ghana and Zimbabwe, it becomes clear that in the general traditional African worldview, land, water, animals and plants are not just production factors with economic significance. They have their place within the sanctity of nature. Moreover, certain places have a special spiritual significance and are used as locations for rituals and sacrifices, for example sacred groves, shrines, mountains and rivers [17] [18]. Fig trees and baobabs are often treated as sacred trees. The sun, moon and stars feature prominently in myths and beliefs of many people. Certain animal species have a spiritual significance too especially in the case of totems. Cattle, sheep, goats and chicken are often used for sacrifices and other religious purposes. McCoy and Ansogtinge, assert that poultry has and still plays important social and cultural roles especially in the life of rural people, not least for building social relations [8] [19]. Creeping wild animals frequently feature in religious concepts. Snakes, lizards, chameleons and certain birds are considered to be messengers of the spiritual world.

Rain is regarded by African peoples to be one of the greatest blessings of God, who is often referred to as the "giver-of-rain". Many of them make sacrifices, offerings and prayers to God in connection to rain. Rainmakers are reported in all parts of the continent. Their duties are to solicit God's help in providing rain or in halting it if too much of it falls or when there is an event such as funeral among the Dagaare and it is felt that the rain would disrupt it.

These worldviews have resulted in the development of knowledge, knowing and their epistemologies. A study of the Cosmovision concept has resulted in the following constellations of forms of body of African knowledge (as depicted in Figure 1) which precedes the findings/results and then the conclusion and recommendations.

The three (3) circles as in Figure 1 are depicting the African worldviews which centre mainly on the human, spiritual and natural.

Social/Human World, Spiritual World, and the Natural World and the interaction of the three worlds imply the following constellations of knowledge: 


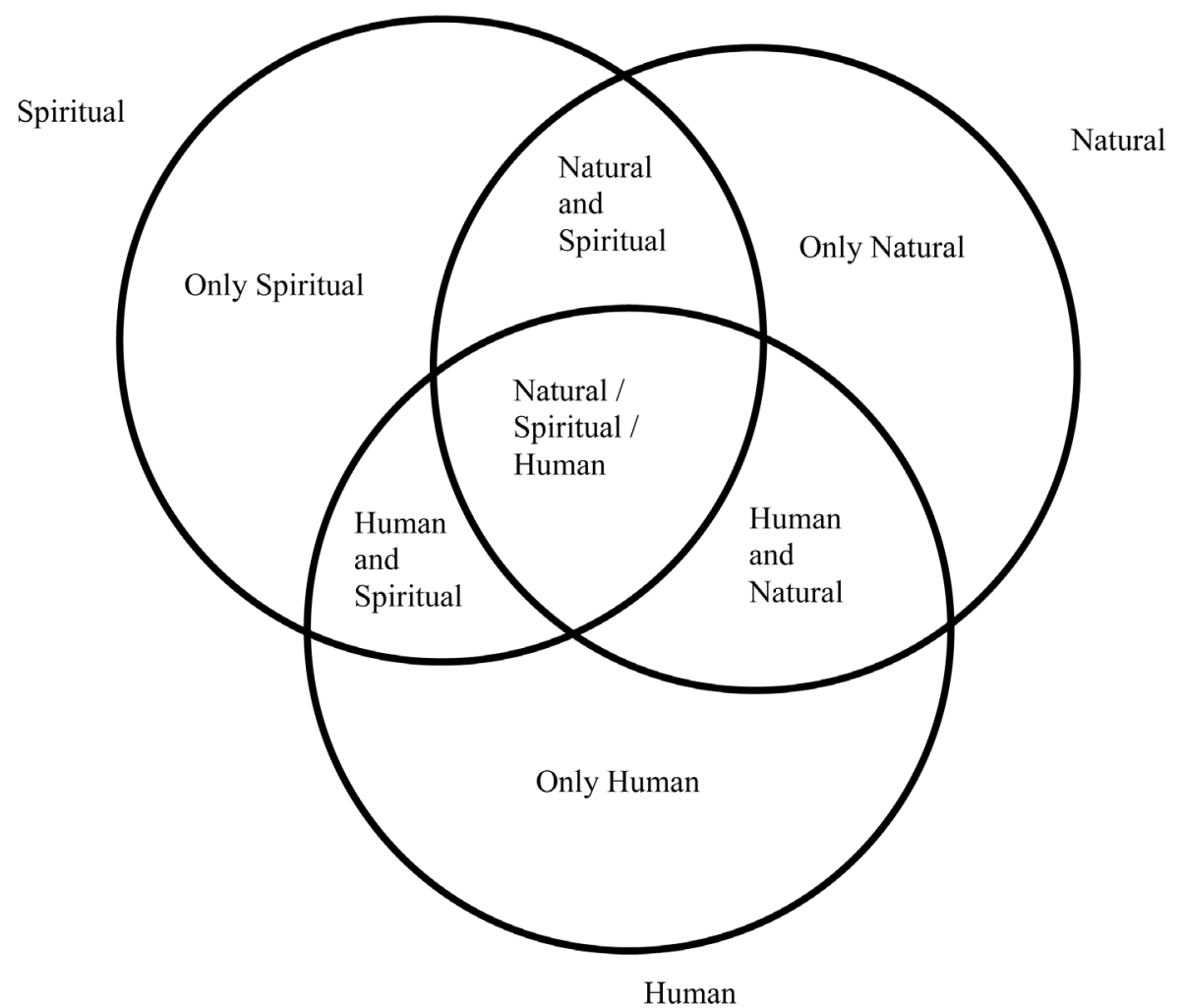

\section{Figure 1. Constellations of knowing from a cosmovision perspective [20].}

- Knowledge resulting from Social interactions only.

- Combination between the Social and Natural.

- Combination between the Social and Spiritual.

- Knowledge resulting from Natural interactions only.

- Combination of the Natural and Spiritual.

- Knowledge resulting from Spiritual only.

- Combination of Social, Spiritual, and Natural. This is the most cherished and sought. This last constellation is the perfect state which strives to be in balance or harmony with itself.

These constellations highlight the heterogeneity and complexities of African Sciences and therefore engendering different bodies of knowledge and sciences that underscore the development of Africa and this contrasts the western science.

Conventional research has concentrated on the 'horizontal level'-the Social and the Material. The investigations or researches of the African in the context of the heterogeneity and complexities ought to be composite/ holistic; targeted at the 'horizontal level' but especially the 'vertical' which deals with higher order discoursesthe spiritual aspect of the African culture.

\section{Discussion}

Within the Compas framework, the Pan African component has recognized the attributes of the weaknesses in African sciences to be historical. In our work, we traced the weaknesses to the following causes:

$>$ The effect of Colonialism and globalization that undervalued the knowledge of the African and succeeded in dividing its peoples and demonized its knowledge base. According to [21] and Murithi as cited [22], development efforts have been western-styled, top-down and even if traditional methods are integrated/incorporated, it never evolved from the people. According to Murithi, as cited in [21], an example is the use of the Somali tradition of shir (gatherings) by the United Nation (UN). While the traditional mode or form is bottom-up, an inclusive process and experienced mediators and trusted elders are used. Talks proceed according to open timetable and social treaties (xeer) are arrived at through consensus and elders with authority and 
power are entrusted to ensure implementation of the agreements. The UN's version is always a top-down process, held outside the country, unequal representation, lack of confidence in the representatives, politician instead of elders, shorter and non-open timetable and no xeer reached as outcome.

> The role of dominant religions (Islam and Christianity) that rejected traditional beliefs, traditional religions, learning and knowing.

$>$ The role of western education that has westernized our ways of knowing to the disadvantage of our Africaness. This compelled us (the schooled) to further undervalue our sciences.

$>$ The little involvement of the Africans in their own knowledge development processes both in situ and exitu.

$>$ A mind-set that makes us not to believe in ourselves.

In addressing these shortcomings in our knowing systems, the scholars in Africa need to:

> Go back to our roots-“"A return to the Village".

$>$ De-school and re-school ourselves.

$>$ Be proud of our Africaness.

$>$ Documenting our cosmovision-based knowledge and making it known that it is not static.

$>$ Develop our own system of knowledge generation and dissemination that incorporates our spirituality as well (and also developing our oral tradition).

$>$ Evolve our own philosophy based on concepts like Ubuntu, Vodou, Saakumnu, Amaamere, Nyaba-Itgo, and others.

> Enroll traditional institutions and help to reconstruct knowing systems, tutelage, and apprenticeship.

$>$ Developing systems of investigation that will enable us better understand, deepen our understanding of our so called "secrecy of our knowledge or knowledge shrouded in mystery".

Dnhance and develop various forms of recording, particularly indigenous forms.

$>$ Involve local experts (spirit mediums) as researches in the knowledge development processes.

$>$ Develop our own indigenous tools and protocols of our "knowing systems" that incorporated to a limited extent, other forms of knowing (also from the west/north).

\section{Conclusions}

This is a frantic attempt to lobby for and a challenge for a new type of African scholarship in both the sciences and the humanities using as a basis the elements of spirituality, Cosmovisions, and the worldviews of Africa. It is the conviction of the paper that, if Africa is to make a significant presence in the "knowledge arena" (if not dominate it), the strength of it is in the indigenous knowledge and the cultures of Africa.

The paper is not only articulating an activist position or belief, but a pragmatist position; harnessing indigenous knowledge in research, teaching, development, and policy works. The paper is also a political instrument requiring the development of a critical mass as faithful disciples to help in carrying this cross else this cry becomes crying in the wilderness. There is a call for new paradigm for higher education; visions for tomorrow's Africa as articulated with critical questions for consideration in the recommendation below.

\section{Recommendations}

A "new type of scholar"-scholarship that combines indigenous knowledge with external knowledge at a collegial level is needed. One way to achieve this is to address the need for doing more and perfecting research and learning from an endogenous development perspective; a development as localized change that is essentially initiated from within (the communities), a development thatmobilizes and harnesses local resources, and retain benefits within the locality and a development which consists of a set of collective capacities to undertake local initiatives that are determined, and controlled by local people and communities, to improve their well-being, drawing from both internal and external resources. A broad spectrum education reform is required and this must starts from the community, through the classroom to the laboratory.

In addressing these shortcomings in our education systems we (the schooled) in Africa need to:

- At the community level, re-vitalize indigenous forms and systems of learning giving due recognition and position to local experts and integrating them into formal systems or according them the same position as the formal system.

- Initiate and advocate a review of didactics at primary and secondary level that build upon our oral traditions, music, art, culture, metallurgy. 
- Re-organize curriculum within the Universities leading to the evolution of professionals and practitioners within an African culture context that will provide "new teaching, learning, research, and community service".

- Develop less formal and less classroom type interactions to create collegial learning among professionals, practitioners, and traditional experts (also spirit mediums).

- Develop, in addition to action and other forms of formal research, indigenous forms of experimentation that recognize rural people as experts, capture our spirituality and our Cosmovisions.

- Ensure communities re-define the roles of University in a more meaningful engagement leading to an inclination towards "Open University systems" that are community-specific in their scholarships.

- Promote African University-wide linkages/collaborations/networks with the view to developing a "Virtual University" in endogenous development.

- Provide opportunities for multiple means of documentation, including traditional knowledge in current curriculum, and integrating traditional knowledge emanating from within the African culture.

The Critical questions that Africa has to deal with include the following among others:

- Are the African Scientists ready to integrate or give due recognition and reward the traditional specialists?

- How can African sciences be taught in schools given the environment of mistrust that has led to mysticism of African sciences? Who teaches it?

- The challenge is teaching African science in developing/adapting methodologies which serve the purpose. How do we encourage joint learning rather than how do we teach?

- In conceptualizing what African sciences are about:

- There is the need to share the strengths of oral tradition as well.

- The knowledge and skill behind oral tradition.

- The ontology behind oral tradition.

- What was there in Africa prior to the advent of western styled documentation?

- What does documentation actually mean? Should this not be elaborated to include paintings, artifacts, designs, drawing, songs, proverbs, stories, rituals, festivals, and spiritually inspired forms of recordings such as dirges, trance, speaking in tongues?.

- Difficulty with African research is in its secretiveness and the absence of a common language.

\section{References}

[1] Millar, D. and Haverkort, B. (2005) African Knowledges and Sciences: Exploring the Ways of Knowing of SubSaharan Africa. In: Millar, D., Kendie, S.K., Apusigah, A.A. and Haverkort, B., Eds., African Knowledges and Sciences Understanding and Supporting the Ways of Knowing in Sub-Saharan Africa, BDU, Barneveld, 11-37.

[2] Mbeki, T. (1996) I Am an African, Statement on Behalf of the African National Congress on the Occasion of the Adoption by the Constitutional Assembly of the Republic of South Africa Constitution Bill. Cape Town.

[3] Jana, P. (2001) African Renaissance and the Millennium Action Plan. Quest, 15, 41-46.

[4] Emegiawali, G. (2003) African Indigenous Knowledge Systems: Implications for curriculum, in Ghana in Africa and the World. Essays in Abu Boaden, F.T., Ed., African World Press.

[5] Goduka, I. (2000) African/Indigenous Philosophies: Legitimizing Spirituality-Centred Wisdoms within the Academy. Central Michigan University, Mount Pleasant.

[6] Weredu, K. (2005) Toward Decolonizing African Philosophy and Religion. African Studies Quarterly, 1, 17-46.

[7] Tengan, E.B. (1994) The Social Structure of the Dagara. The House and the Matriclan as Axes of the Dagara Social Organization. The Victor's Series: Tamale.

[8] McCoy, R.F. (1988) Great Things Happen a Personal Memoir. Society of the Missionaries of Africa, Canada.

[9] Kendie, S.B. and Guri, Y.B. (2005) Indigenous Institutions as Partners for Agriculture and Natural Resource Management. In: Millar, D., Kendie, S.K., Apusigah, A.A. and Haverkort, B., Eds., African Knowledges and Sciences Understanding and Supporting the Ways of Knowing in Sub-Saharan Africa, BDU, Barneveld, 106-128.

[10] Lingard, L., Albert, M. and Levinson, W. (2008) Qualitative Research. Grounded Theory, Mixed Methods, and Action Research. www.bmj.com

[11] Charmaz, K. (2012) The Power and Potential of Grounded Theory. A Journal of the BSA MedSoc Group. www.medicalsociologyonline.org

[12] Wilson, R.T. (1995) Distribution and Importance of Livestock in the Tropics. In: Coste, R. and Smith, A.J., Eds., Livestock Production Systems, Macmillan Education Ltd., London, 1-12. 
[13] Adler, J. and Lawler, A. (2012) How the Chicken Conquered the World. Smithsonian Magazine. www.smithsonianmag.com/history-archaeology/How-the-Chicken-Conquered-the-World.html\#ixzz2ZoFKIDVh

[14] Mbakogu, I.A. (2004) Is There Really a Relationship between Culture and Development? Anthropologist, 6, 37-43.

[15] Mbanda, L. (1997) Committed to Conflict: The Destruction of the Church in Rwanda. Cromwell Press.

[16] Haverkort, B. and Hiemstra, W. (1999) Food for Thought: Ancient Visions and New Experiments of Rural People. Zed Books, London.

[17] Millar, D. (1999) Traditional African Worldviews from a Cosmovision Perspective. In: Haverkort, B. and Hiemstra, W., Eds., Food for Thought: Ancient Visions and New Experiments of Rural People, Zed Books, London.

[18] Gonese, C. (1999) The Three Worlds. COMPAS Newsletter, No. 1.

[19] Ansogtinge, G. (1986) The Wisdom of the Ancestors: The Dagaaba and Storytelling Events. Doctor of Philosophy (PhD) Thesis, 16-82.

[20] Millar, D. (2006) Ancestor Centrism: A Basis for African Sciences and Learning Epistemologies. In: African Knowledges and Sciences: Understanding and Supporting the Ways of Knowing in Sub-Saharan Africa.

[21] Kirby, J.P. (2002) Culture-Drama and Peace Building. Ghana Institute of Linguistics, Literacy and Bible Translation (GILLBT), Tamale.

[22] Malan, J. (2005) Traditional and Local Conflict Resolution. In: van Tongeren, P., Brenk, M., Hellema, M. and Verhoeven, J., Eds., People Building Peace II Successful Stories of Civil Society, Lynne Rienner, Boulder, 449-466. 